\title{
Water Security in The Arab World (Demand and Supply)
}

\author{
Mohamed Elhag* \\ Department of Hydrology and Water Resources Management, Faculty of Meteorology, Environment and Arid and Agriculture, King Abdul Azziz University, Saudi Arabia \\ *Corresponding author: Mohamed Elhag, Department of Hydrology and Water Resources Management, Faculty of Meteorology, Environment and Arid Land \\ Agriculture, King Abdul Azziz University, Saudi Arabia, Tel: +966-0-55765368; Fax: +966-02-6952364; E-mail: stkranger@yahoo.com
}

Rec date: Oct 16, 2014; Acc date: Oct 16, 2014; Pub date: Oct 23, 2014

Copyright: $\odot 2014$ Elhag M. This is an open-access article distributed under the terms of the Creative Commons Attribution License, which permits unrestricted use, distribution, and reproduction in any medium, provided the original author and source are credited.

\section{Introduction}

Arab countries are located in arid environments and semi-arid areas where these environments are characterized by the contrast in temperature between extreme heat in summer and cold in winter, and also these environments are characterized by seasonal rains are scarce and scattered in most days of the year. Arab countries described by scarce resources of freshwater in number of rivers and freshwater lakes, only three major rivers namely River Nile and the Tigris and Euphrates rivers and a number of subsidiary rivers that located in each of the Levant, as well as the Maghreb, but for the lakes recalled including Lake Nasser and Lake Tiberias only. But both rivers and freshwater lakes is not sufficient to meet the growing needs of the sources of fresh water for the region's countries.

Conflicts arise between the States participating in the water sources of the inability of those sources to meet the needs of those countries and this is what caused the emergence of a number of regional conflicts in the past decade, as the nature of water resources is different from many of the other natural resources in being the resources of transboundary that crosses a state or more, which makes the management of these resources is always a difficult task because it requires a lot of cooperation and integration between the participating states in water sources and represents the major rivers in the Arab world clearest example of the nature of those resources.

Usually traditional solutions fails to resolve such regional conflicts based on the facts that those conflicts are dynamic therefore needed to find unconventional solutions to ensure preservation of the concept of sustainability in the management of water resources without resorting to conflicts and disputes between countries in the region.

\section{Facts and Axioms}

The atmosphere around the globe makes their vital and non-vital systems closed does and doesn't not allow the courtyard or the development of component materials for these systems, and an example of this, the amount of water on the Earth's surface are the same since God created the earth, the only changes are the state and/or the quality of water, thus the problems lies in the fact that water is available or not available.

Available source is the source that ensures the direct use of water without the need for effort or treating, for example, evaporation in the atmosphere is a source of water and needs a lot of effort to make it accessible, and also wastewater of domestic and agricultural sectors considered as water sources but needs multiple stages of processing to become available for human use
Based on the foregoing, is the water crises in the Arab world are true or fabricated crises? Unfortunately there is no one conclusive answer to such a question, but can be summarized in this matter that the concocted crises due to poor management of water resources in those countries. For deeper clarification, the major consumption of water resources in the Arab world is the agriculture sector, which could be up to $80 \%$ of the total available water resources in some countries in the region so most of the adopted agricultural practices need to be reviewed.

\section{Unconventional Solutions}

In order to avoid regional conflicts and geopolitical crises between countries in the region is to encourage the participating States in the available water resource, especially rivers and aquifers, must work on the principle of joint integration and interdependence of the diaper on those sources. Since the conflicts of water resources scarcity arising from is a geopolitical conflicts also solutions must be geopolitical solutions.

The highlight of use of modern non-traditional applications to solve such problems are mainly directed toward the applications of remote sensing and geographic information systems, which are already applied in some countries in the region but its applied at the local level and not at the regional level. The use of such modern applications provides an opportunity to re-allocate water in a way to ensure the enforcement of the concepts of sustainable use of water resources.

Although fresh water resources in Arab countries are limited but all of the Arab states are coastal States, means that Arab countries have another source of dominant and abundant of unavailable water. This requires those countries to pursue conversion of these resources to be available resources, Arab States will not leads in this field, membrane technologies are already in the region, the largest seawater desalination planet using membrane technologies produces about five hundred million cubic meters per year and is the biggest station in Middle East.

The techniques of desalination of sea water using plasma membranes are becoming cleaner and technical optimization in terms of their need to reverse osmosis seawater only mechanical pressure greater, and there leading countries in the world possess such technologies across multiple stages of study and research. In this task be concerned Arab countries to choose and develop and what suits the needs of those countries from the water. 